\title{
Microcrystalline silicon solar cells deposited at high rates
}

\author{
Y. Mai, ${ }^{\text {a) }}$ S. Klein, R. Carius, J. Wolff, A. Lambertz, and F. Finger \\ Institut für Photovoltaik (IPV), Forschungszentrum Jülich GmbH, D-52425 Jülich, Germany \\ X. Geng \\ Institute of Photoelectronics, Nankai University, Tianjin 300071, People's Republic of China
}

(Received 21 January 2005; accepted 6 April 2005; published online 3 June 2005)

\begin{abstract}
Hydrogenated microcrystalline silicon $(\mu c-\mathrm{Si}: \mathrm{H})$ thin-film solar cells were prepared at high rates by very high frequency plasma-enhanced chemical vapor deposition under high working pressure. The influence of deposition parameters on the deposition rate $\left(R_{D}\right)$ and the solar cell performance were comprehensively studied in this paper, as well as the structural, optical, and electrical properties of the resulting solar cells. Reactor-geometry adjustment was done to achieve a stable and homogeneous discharge under high pressure. Optimum solar cells are always found close to the transition from microcrystalline to amorphous growth, with a crystallinity of about $60 \%$. At constant silane concentration, an increase in the discharge power did hardly increase the deposition rate, but did increase the crystallinity of the solar cells. This results in a shift of the $\mu c-\mathrm{Si}: \mathrm{H} / a-\mathrm{Si}: \mathrm{H}$ transition to higher silane concentration, and therefore leads to a higher $R_{D}$ for the optimum cells. On the other hand, an increase in the total flow rate at constant silane concentration did lead to a higher $R_{D}$, but lower crystallinity. With this shift of the $\mu c-\mathrm{Si}: \mathrm{H} / a-\mathrm{Si}: \mathrm{H}$ transition at higher flow rates, the $R_{D}$ for the optimum cells decreased. A remarkable structure development along the growth axis was found in the solar cells deposited at high rates by a "depth profile" method, but this does not cause a deterioration of the solar cell performance apart from a poorer blue-light response. As a result, a $\mu c$-Si:H single-junction $p-i-n$ solar cell with a high efficiency of $9.8 \%$ was deposited at a $R_{D}$ of 1.1 nm/s. (C) 2005 American Institute of Physics. [DOI: 10.1063/1.1927689]
\end{abstract}

\section{INTRODUCTION}

High growth rate of microcrystalline silicon $(\mu c-\mathrm{Si}: \mathrm{H})$ with plasma-enhanced chemical vapor deposition (PECVD) requires reasonably high discharge power for high dissociation of the reactant gases, leading to higher sheath voltages, and thus higher ion energy. High-energy ions impinging on the growth surface, however, are considered to be detrimental to the quality of $\mu c-\mathrm{Si}: \mathrm{H}$, causing defect formation and deterioration in crystallinity. ${ }^{1,2}$ Therefore, suppressing the high-energy ions in the plasma is of particular necessity at a high deposition rate $\left(R_{D}\right)$. A way to reduce ion energies in PECVD systems is the use of a third electrode in a triode arrangement. ${ }^{1,3,4}$ With an independent bias on this electrode with respect to the grounded substrate, ion energies can be controllably reduced. Other effective methods to reduce ion energies while maintaining high deposition rates are (i) very high frequency (VHF) excitation of the discharge, where lower peak-to-peak voltages for a given discharge power result in lower maximum-ion energies, ${ }^{5-9}$ and (ii) high working pressure $\left(p_{\text {depo }}\right)$ with an increased discharge power, where ion energies are reduced by multiple collisions in the plasma sheath. ${ }^{10-12}$ Recently, also combinations of VHF-PECVD and high working pressure have been investigated. ${ }^{3,13-17}$ In the present paper we report on further studies of such a combination of VHF-PECVD at $94.7 \mathrm{MHz}$ at high working pressures of $2-4 \mathrm{hPa}$ for the growth of $\mu c-\mathrm{Si}: \mathrm{H}$ at high deposi-

\footnotetext{
${ }^{\text {a) }}$ Author to whom correspondence should be addressed; also at the Institute of Photoelectronics, Nankai University, Tianjin 300071, P. R. China; electronic mail: y.mai@fz-juelich.de
}

tion rates. As high pressure is combined with high discharge power, we shall refer to this deposition regime as high pressure-high power (hphP) in contrast to the low powerlow pressure (lplP) conditions in conventional RF- and VHFPECVD.

While the reduction of the ion energies by a combination of high excitation frequency and high working pressure is successfully reducing the damage on the growing surface, such energy loss and unwanted leak discharges can, on the other hand, result in disruption of the glow discharge. Therefore, a discharge reactor geometry adjustment, different from the optimum settings in RF- or VHF-PECVD at low $p_{\text {depo }}$ (typically $0.3 \mathrm{hPa}$ ), is generally necessary at high $p_{\text {depo }}$. This will first be discussed in this report. After having defined a reactor geometry for a stable and homogeneous discharge, deposition of $\mu c-\mathrm{Si}: \mathrm{H}$ absorber layers in $p-i-n$ solar cells are carried out with variations of the discharge power $P_{\mathrm{VHF}}$, the working pressure $p_{\text {depo }}$, and the total gas flow rate $F l_{\text {total }}$. For each set of deposition condition, the silane concentration (SC) is varied so as to cover the entire range of material growth from highly crystalline to amorphous, in order to find the optimum phase mixture (OPM) material. Such OPM material, which results in the highest solar cell efficiencies, was found close to the transition from highly crystalline to amorphous growth in several earlier studies with different deposition methods. ${ }^{12,18,19}$ Here we show that a similar behavior is found for the VHF-PECVD under high working pressure and high power (hphP) conditions. The shift of the OPM growth regime upon the variation of the deposition conditions, such as power and gas flow, and the behavior of the 


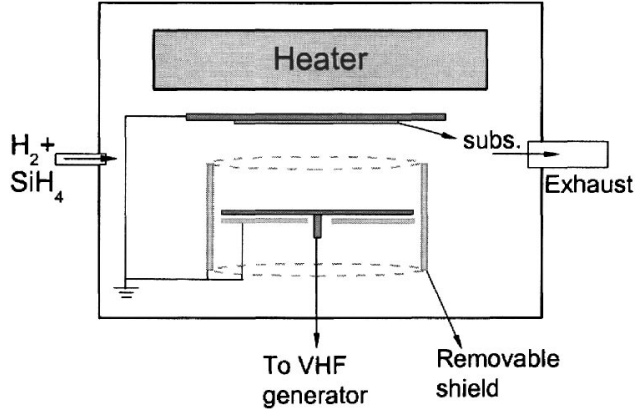

FIG. 1. Schematic picture of the PECVD deposition chamber.

growth rates shall be discussed with an illustrative scheme for $\mu c-\mathrm{Si}: \mathrm{H}$ growth, with the ratio of $\mathrm{H}$ over $\mathrm{SiH}_{x}(x=1,2$, or 3 , same hereinafter) radicals as the key parameter.

On the other hand, the solar cell performance is related to the $i$-layer material properties. For this purpose, in addition to current-voltage $(J-V)$ measurements on the solar cells under illumination, measurements of the quantum efficiency $(\mathrm{QE})$ and of the dark $J-V$ are performed. Points of concern when using high-deposition-rate methods are that material growth might be affected by the insufficient relaxation of growth precursors and the development of a pronounced disordered interface between the $p$ and the $i$ layers in the case of a $p-i-n$ junction. This would affect the solar cell performance through reduced carrier collection and would show as a reduced blue-light response. Therefore, we have investigated, in particular, the structure composition of the absorber-layer material and the development of the structure along the growth axis with Raman spectroscopy. For the latter a powerful "depth profile" method, including crater etching and Raman-scattering measurements with different excitation wavelengths, is introduced.

\section{EXPERIMENTAL DETAILS}

The $p, i$, and $n$ layers of the $\mu c-\mathrm{Si}: \mathrm{H}$ solar cells were deposited in individual chambers of a cluster-tool deposition system $^{20}$ by PECVD to form $p-i-n$ single-junction diodes. Figure 1 shows a schematic picture of the deposition chamber. The electrode configuration consists of a $13.5-\mathrm{cm}-$ diameter powered electrode and a $12 \times 12-\mathrm{cm}^{2}$ substrate carrier in a carrier support as the grounded electrode. Substrate size is $10 \times 10 \mathrm{~cm}^{2}$. The electrode distance is easily variable in situ between 60 and $12 \mathrm{~mm}$. A metal shield around the electrodes to prevent deposition on the chamber walls, as indicated in Fig. 1, can be removed for discharge adjustment. The gas supply is a simple cross-flow geometry, i.e., no gas showerhead arrangement.

Solar cells are deposited on texture-etched $\mathrm{ZnO}$-coated glass substrates. ${ }^{21}$ Substrate temperatures are $\sim 200{ }^{\circ} \mathrm{C}$ for $p$-, $i$-, and $n$-layer depositions. The $\mu c-\mathrm{Si}: \mathrm{H} p$ and $i$ layers were deposited with VHF-PECVD at $94.7 \mathrm{MHz}$. The $a$-Si:H $n$ layers were deposited with conventional RF-PECVD at 13.56 MHz. The silane concentration, $\mathrm{SC}=\left[\mathrm{SiH}_{4}\right] /\left(\left[\mathrm{SiH}_{4}\right]\right.$ $\left.+\left[\mathrm{H}_{2}\right]\right)$, defined by the gas-flow ratio of silane and hydrogen was varied in each case to adjust the structure mixture of the $i$-layer material from highly crystalline to amorphous.

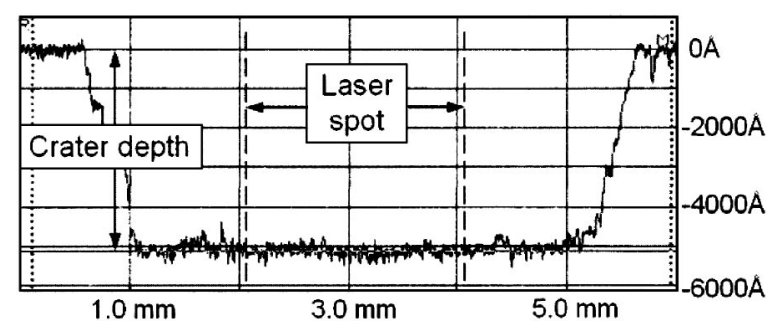

FIG. 2. Depth profile of a crater etched with $\mathrm{KOH}$ solution into a $p-i-n$ solar cell structure. The dimension of the laser spot in the Raman-scattering measurement is also indicated.

The area of individual solar cells is defined by the 1 $\times 1-\mathrm{cm}^{2}$ evaporated $\mathrm{Ag}$ back contact. The deposition time for the $i$ layers was adjusted to obtain a thickness of approximately $1 \mu \mathrm{m}$. The thickness of the solar cells was measured with a step profiler (Dektak 3030, VEECO Instruments $\mathrm{GmbH}$ ), neglecting the thickness of the doped layers (total of about $50 \mathrm{~nm}$ ). The deposition rate was calculated from the thickness measurement in the center of the substrate. The thickness variation between the center and the edge of the substrate was typically about $10 \%$. The $J-V$ characteristics of the solar cells, i.e., efficiency $\eta$, open-circuit voltage $V_{\mathrm{OC}}$, fill factor FF, and short-circuit current density $J_{\mathrm{SC}}$, were measured under AM1.5 illumination at $25{ }^{\circ} \mathrm{C}$ after a 30-min annealing in air at $160{ }^{\circ} \mathrm{C}$. The $J-V$ curves measured in the dark are used to obtain information about the recombination behavior in the solar-cell absorber layers. ${ }^{22-24}$ Quantum efficiency spectra are used for information about the optical absorption and the charge-carrier extraction. ${ }^{25,26}$

Raman-scattering measurements performed on the solar cells, after the removal of the amorphous $n$ layers by $\mathrm{KOH}$ etching, provide direct information about the relationship between the structural properties and solar cell performance. The 488-nm line of an argon laser is usually used for excitation, and more than $50 \%$ of the Raman signal at this wavelength was contributed from the topmost $200 \mathrm{~nm}$ of the $i$ layer. In order to find out the structure evolution in the growth direction, a depth-profile method is introduced here. Craters with different depths created by $\mathrm{KOH}$ etching make it possible to obtain the structure information at different stages of growth directly by Raman-scattering measurement. Choosing the appropriate $\mathrm{KOH}$ solution concentration, etching temperature, and etching time, different crater depths with sufficient smoothness at the bottom can be achieved, which can be monitored by the step profiler. Figure 2 shows an exemplary picture of a crater measured by the step profiler. The 4-mm-long and 2-mm-wide flat bottom allows an accurate Raman measurement with the $2 \times 0.3-\mathrm{mm}^{2}$ large laser point. Raman-scattering measurement with a longer excitation wavelength of $647 \mathrm{~nm}$, with most of the signal contributed from the topmost $1 \mu \mathrm{m}$ of the $i$ layer in the solar cells, here the whole $i$ layer, is used as an easy and supplementary method to the crater etching. The ratio of the integrated intensities of Gaussian peaks fitted to the Raman signal attributed to crystalline grains (at 500 and $520 \mathrm{~cm}^{-1}$ ) and disordered regions $\left(480 \mathrm{~cm}^{-1}\right), I_{C}{ }^{\mathrm{RS}}=\left(I_{500}+I_{520}\right) /\left(I_{480}+I_{500}\right.$ $\left.+I_{520}\right)$ is used as a semiquantitative value of the crystalline 
TABLE I. Deposition parameters of the silane concentration (SC) series.

\begin{tabular}{|c|c|c|c|c|c|c|}
\hline Series name & $\begin{array}{l}p_{\text {depo }} \\
(\mathrm{hPa})\end{array}$ & $\begin{array}{c}P_{\mathrm{VHF}} \\
(\mathrm{W})\end{array}$ & $\begin{array}{c}F l_{\text {total }} \\
(\mathrm{SCCM})\end{array}$ & $\begin{array}{c}d \\
(\mathrm{~mm})\end{array}$ & Shield & $p$ layer \\
\hline hphP $20 \mathrm{~W}$ & 2.1 & 20 & 100 & 12 & with & Normal \\
\hline hphP $30 \mathrm{~W}$ & 2.1 & 30 & 100 & 12 & with & Normal \\
\hline hphP $40 \mathrm{~W}$ & 2.1 & 40 & 100 & 12 & with & Normal \\
\hline hphP $60 \mathrm{~W}$ & 2.1 & 60 & 100 & 12 & with & Normal \\
\hline hphP $90 \mathrm{~W}$ & 2.1 & 90 & 100 & 12 & with & Normal \\
\hline hphP $19 \mathrm{~mm}$ & 2.1 & 60 & 100 & 19 & with & Normal \\
\hline hphP $4 \mathrm{hPa}$ & 4.0 & 60 & 100 & 12 & with & Normal \\
\hline hphP 100 SCCM & 2.1 & 60 & 100 & 12 & w/o & Improved \\
\hline hphP 200 SCCM & 2.1 & 60 & 200 & 12 & w/o & Improved \\
\hline hphP 400 SCCM & 2.1 & 60 & 400 & 12 & w/o & Improved \\
\hline lplP & 0.25 & 10 & 100 & 19 & w/o & Improved \\
\hline
\end{tabular}

Note: $1 \mathrm{hPa}=1 \mathrm{mbar}$

volume fraction. ${ }^{27,28}$ We use $I_{C}{ }^{\mathrm{RS}}{ }_{488}$ and $I_{C}{ }^{\mathrm{RS}}{ }_{647}$ to specify the $I_{C}{ }^{\mathrm{RS}}$ values calculated from Raman spectra with 488 and 647-nm excitation, respectively.

\section{RESULTS}

\section{A. High-rate deposition under hphP condition}

In the first part, investigations of the influence of the deposition parameters, such as $P_{\text {depo }}, P_{\mathrm{VHF}}, F l_{\text {total }}$, and electrode distance $d$, on the discharge stability, the deposition rate $R_{D}$, and the solar cell properties will be presented. For the individual deposition conditions, variations of the silane concentration SC were performed to cover the range from highly crystalline to amorphous growth and to obtain the optimum solar cells. For a detailed information on the deposition parameters in each SC series, see Table I. The first column shows the names assigned to the SC series, which will be used hereafter for the presentation and discussion of the results. Data for one series of solar cells deposited under low-pressure, low-power (lplP) conditions at $R_{D}$ between 0.12 and $0.35 \mathrm{~nm} / \mathrm{s}$ are also presented for comparison. $R_{D}$ and the conversion efficiency for the optimum solar cell in the lplP series are about $0.2 \mathrm{~nm} / \mathrm{s}$ and $8 \%$, respectively. The results for this lplP series are in excellent agreement with earlier work, and the solar cell parameters show the wellknown behavior as a function of SC, i.e., the variation of the crystalline volume fraction. ${ }^{18}$

In the hphP series with different $F l_{\text {total }}$ and in the lplP series, an improved, thinner $p$ layer, yielding higher bluelight response, is used. In the $i$-layer deposition of these solar cell, the metallic shield around the powered electrode was removed to obtain more stable deposition conditions. This will be discussed in the following section.

\section{Stable and homogeneous deposition under high $\boldsymbol{p}_{\text {depo }}$}

Deposition processes in the hphP regime promise a considerable increase in the growth rate, but the low electron energy, caused by a reduced mean free path under highpressure conditions and by a low peak-to-peak voltage at high plasma-excitation frequency, make it difficult to start and sustain stable discharges. For this reason, an adequately high discharge power and/or a small electrode distance are necessary for the combination of VHF and high pressure. Figure 3 shows the minimum power, which is required for a given $p_{\text {depo }}$ in order to maintain a stable plasma at different electrode distances $(d)$. The necessary $P_{\mathrm{VHF}}$ sharply increases with $p_{\text {depo }}$ at a constant electrode distance. At smaller distances, where a stronger electric field is available, lower $P_{\mathrm{VHF}}$ is sufficient at a given $p_{\mathrm{depo}}$. All combinations of $P_{\mathrm{VHF}}$ and $p_{\text {depo }}$ yielding stable plasma conditions should be located above the corresponding line for a given electrode distance. Leading to high $R_{D}$ and simultaneously providing a wide deposition parameter space within the system's technical limit, the pressure of $2.1 \mathrm{hPa}$ is the one generally used under the hphP condition in this paper. The removal of the metallic shield resulted in less parasitic losses of the discharge between electrode and shield, requiring a considerable lower minimum power to sustain a stable plasma. As a consequence, also less powder was accumulated at the electrode edges, which in turn led to a better stability of the individual discharge as well as from run to run. Furthermore, it was observed that under high working pressure, the plasma was well confined in between the electrodes, with no plasma burning at other places after the removal of the shield. Therefore, depositions in the later stage of the present research work have been carried out without a shield. The comparison of the solar cell performance showed that the removal of the

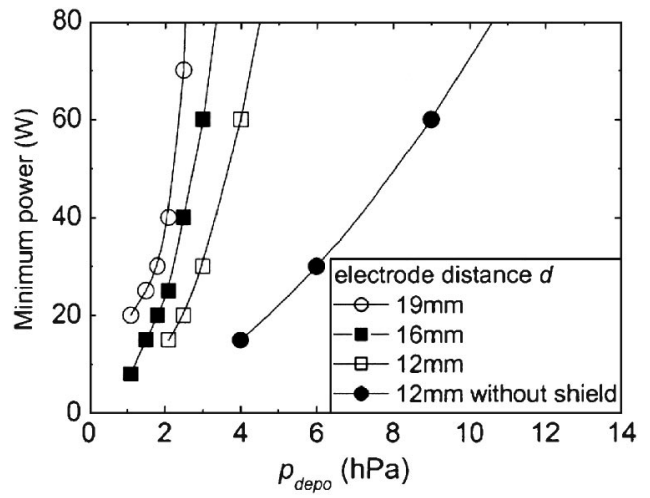

FIG. 3. Minimum discharge powers to sustain a stable discharge as a function of $p_{\text {depo }}$ for different electrode distances. 


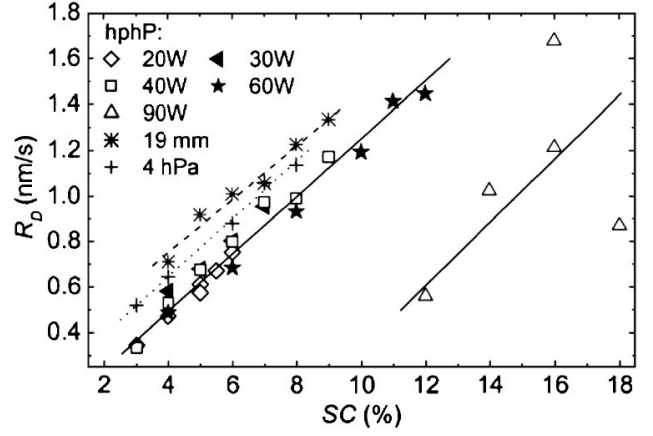

FIG. 4. $R_{D}$ of solar cells deposited with different $P_{\mathrm{VHF}}$ plotted against SC. $p_{\text {depo }}=2.1 \mathrm{hPa}$ and $d=12 \mathrm{~mm}$ were used for most of the series, except for the two series with higher $p_{\text {depo }}$ or larger electrode distance (hphP $4 \mathrm{hPa}$ and hphP $19 \mathrm{~mm}$, respectively).

shield has no major influence on the deposition rate or the solar cell properties, apart from the improved process stability.

In addition, the reduction of the electrode distance also improves the homogeneity of the discharge across the substrate. At an electrode distance of $19 \mathrm{~mm}$, which is the electrode distance $d$ used for VHF-PECVD in the lplP series, already a considerable increase of $R_{D}$ could be achieved by applying high pressure and high $P_{\mathrm{VHF}}$ (e.g., $1.23 \mathrm{~nm} / \mathrm{s}$, optimum cell in hphP 19-mm series), compared to the typical $R_{D}$ $(\sim 0.2 \mathrm{~nm} / \mathrm{s})$ under lplP conditions. However, such samples suffer from strong structural inhomogeneities on a substrate size of $10 \times 10 \mathrm{~cm}^{2}$. By reducing the electrode distance to 12 $\mathrm{mm}$, the homogeneity greatly improved. Relative efficiency variations across the substrate are typically about $10 \%$, except for some solar cells in the corners of substrates in some cases. Therefore, the majority of the investigations in this report were performed with an electrode distance of $12 \mathrm{~mm}$ and $p_{\text {depo }}$ of $2.1 \mathrm{hPa}$.

\section{Effect of $\boldsymbol{P}_{V H F}$ on the $\boldsymbol{R}_{D}$ and solar cell performance}

Five different discharge powers, $P_{\mathrm{VHF}}$ of $20,30,40,60$, and $90 \mathrm{~W}$, were applied to investigate the influence of discharge power on $R_{D}$ and on the properties of $\mu c$ - Si:H solar cells at high deposition pressures. The input and reflected powers are nominal values measured by a directional power meter (Rhode \& Schwartz NAP meter, power head: NZ-4) between the VHF generator and the matching network. To guarantee good power coupling into the discharge, care was taken by using large-diameter cables and a corresponding electric vacuum feed through, short cable lengths, and individually adjusted matching networks. The measured reflected power was typically below $1 \%$. However, the "real" power dissipated in the discharge might be very different from the nominal input power. Details shall not be considered here. The $R_{D}$ of these SC series with different $P_{\mathrm{VHF}}$ are shown in Fig. 4 as functions of SC. In addition, two series of solar cells were prepared with larger electrode distance (hphP 19 $\mathrm{mm})$ or higher $p_{\text {depo }}(\mathrm{hphP} 4 \mathrm{hPa})$ at $P_{\mathrm{VHF}}=60 \mathrm{~W}$. The results for the deposition rates of these series are also plotted in Fig. 4. A linear increase of $R_{D}$ with increasing $\mathrm{SC}$ is observed in all cases. At $P_{\mathrm{VHF}}=90 \mathrm{~W}$, the plasma became unstable and a considerable scatter of $R_{D}$ was observed. Further geometry

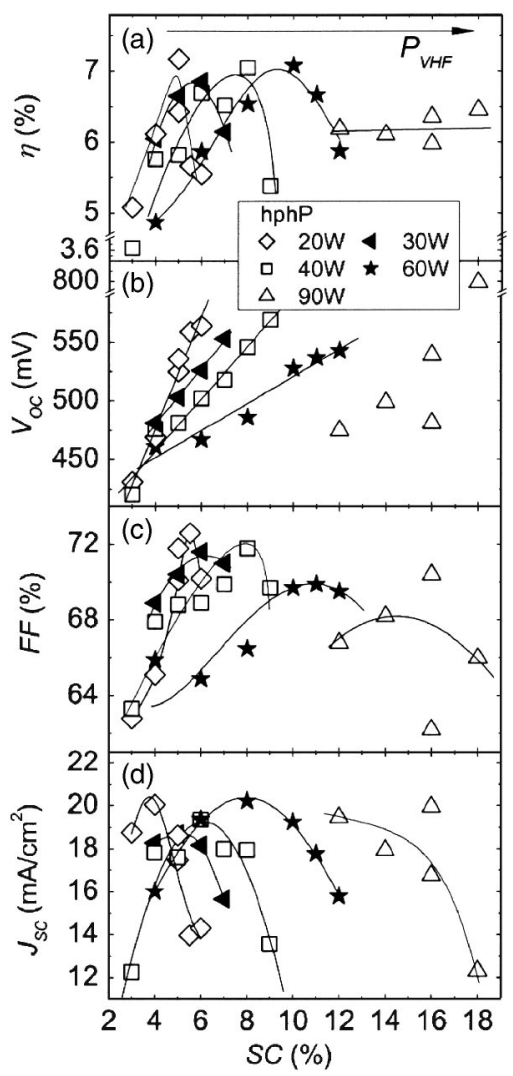

FIG. 5. $J-V$ characteristics (a) $\eta$, (b) $V_{\mathrm{OC}}$, (c) FF, and (d) $J_{\mathrm{SC}}$ under AM1.5 illumination of solar cells deposited under hphP conditions with different $P_{\mathrm{VHF}}$. Samples are the same as those shown in Fig. 4 with $p_{\text {depo }}$ of $2.1 \mathrm{hPa}$ and $d$ of $12 \mathrm{~mm}$. All solar cells are $\sim 1-\mu \mathrm{m}$ thick and $1 \times 1 \mathrm{~cm}^{2}$ large, defined by simple Ag back contacts. The arrow in figure (a) shows the systematic shift of the optimum cells' SC upon the increasing $P_{\mathrm{VHF}}$. The lines are guides to the eyes.

rearrangement is necessary for such high $P_{\mathrm{VHF}}$ for the present reactor design. The increase of $P_{\mathrm{VHF}}$ does not result in any significant increase of $R_{D}$ at a fixed $\mathrm{SC}$ and above a certain $P_{\mathrm{VHF}}, R_{D}$ even decreases. Assuming that up to $60 \mathrm{~W}$ the real power in the discharge at least increases to some extent, such a behavior indicates a depletion of the silane source gas. On the other hand, increasing $p_{\text {depo }}$ or the electrode distance $d$ at a given discharge power of $60 \mathrm{~W}$ results in higher $R_{D}$ for all SC compared with the other series deposited at $2.1 \mathrm{hPa}$ and a 12-mm electrode distance.

Figure 5 shows the $J-V$ characteristics for these series of solar cells deposited with different $P_{\mathrm{VHF}}$ at $2.1 \mathrm{hPa}$. For each $P_{\mathrm{VHF}}$ we observe a similar behavior of $J-V$ parameters for $\mu c-\mathrm{Si}: \mathrm{H}$ solar cells when varying $\mathrm{SC}$, except the scattered results in the hphP 90-W series. FF and $J_{\mathrm{SC}}$ first increase with $\mathrm{SC}$ and drop after reaching the maximum point. $V_{\mathrm{OC}}$ increases almost linearly in the investigated SC range. The solar cells with maximum efficiency are obtained at a $V_{\mathrm{OC}}$ of $540 \mathrm{mV}$. Note that the $J-V$ parameters are taken from the best $1 \times 1-\mathrm{cm}^{2}$ cell of each $10 \times 10-\mathrm{cm}^{2}$ substrate. The low $J_{\mathrm{SC}}$ at high SC is attributed to the red and infrared response loss in these solar cells. This is confirmed by using a cutoff filter during $J-V$ characteristics measurement. The highest FF in each SC series decreases systematically upon the increasing $P_{\mathrm{VHF}}$, but a significant drop of the optimum cell efficiency was only observed at $P_{\mathrm{VHF}}=90 \mathrm{~W}$. The most im- 


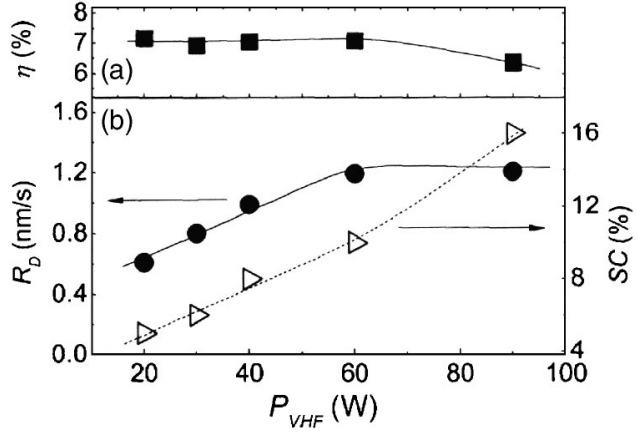

FIG. 6. (a) Efficiencies of the optimum solar cells in the SC series with different $P_{\mathrm{VHF}}$ (b) Corresponding deposition rates $R_{D}$ and $\mathrm{SC}$ of these cells.

portant observation is the shift of the maximum values in efficiency, FF, and $J_{\mathrm{SC}}$ to higher $\mathrm{SC}$ upon the increase of the discharge power. As a consequence, optimum cells deposited with higher $P_{\mathrm{VHF}}$ have higher $R_{D}$, as indicated in Fig. 6, in which efficiency, $R_{D}$, and the required $\mathrm{SC}$ of the optimum cells of these series are plotted versus $P_{\mathrm{VHF}}$. The required SC for optimum solar cells increases linearly with $P_{\text {VHF }}$. The increase of the silane supply leads to a linear increase of $R_{D}$ below $60 \mathrm{~W}$.

The optimum cells of the hphP 19-mm and hphP 4-hPa series show a lower conversion efficiency of about $6 \%$ and a strong structural inhomogeneity over the $10 \times 10-\mathrm{cm}^{2}$ substrates.

\section{Effect of $\mathrm{FI}_{\text {total }}$ on the $R_{D}$ and solar cell performance}

As was shown in Fig. 4, an increase of the discharge power at hphP conditions from 20 to $60 \mathrm{~W}$ does not lead to an increase in the deposition rate at constant SC, while the deposition rate increases linearly with silane concentration, i.e., the source gas supply. This points to the silane depletion under these conditions. It means that at a given SC, the precursor density cannot be increased much by a higher discharge power. A possible solution to this problem would be to increase the reaction zone volume or to increase the silane supply by a higher gas flow. As an additional beneficial effect of a higher gas flow, powder formation, which is frequently observed in high-deposition-rate processes, could possibly be suppressed due to the resulting short gas residence time. Three different $F l_{\text {total }}, 100,200$, and 400 SCCM (standard cubic centimeter per minute), were used to prepare $\mu c$-Si:H solar cells at a discharge power of $60 \mathrm{~W}$ and a pressure of $2.1 \mathrm{hPa}$. Again, SC series were done to cover the range from a highly crystalline to an amorphous material structure. Furthermore, the metallic steel shield around the powered electrode was removed in the $i$-layer deposition. Figure 7 shows the $R_{D}$ of the solar cells deposited at different flow rates, plotted against SC. A linear increase of $R_{D}$ with increasing $\mathrm{SC}$ is observed at each different $F l_{\text {total }}$. At constant $\mathrm{SC}$, doubling $F l_{\text {total }}$ increases, but far from doubles, the $R_{D}$, resulting in lower gas utilization at higher $F l_{\text {total }}$. The comparison with the hphP 60-W series, shown in Fig. 4, which was deposited with the metallic shield, shows that the removal of the shield makes no difference in the $R_{D}$.

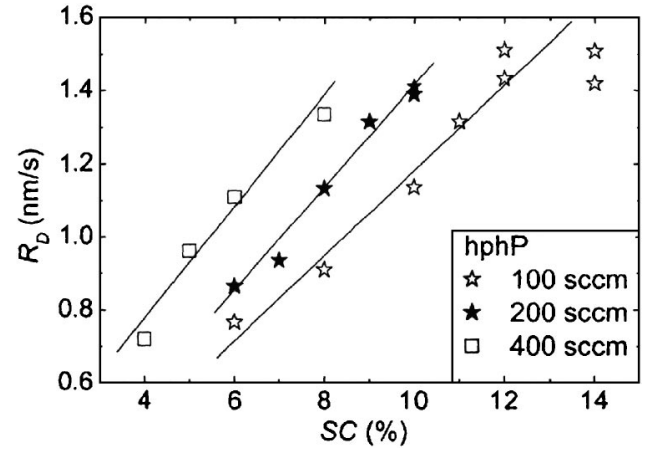

FIG. 7. $R_{D}$ of solar cells deposited with different $F l_{\text {total }}$ plotted as a function of SC.

The $J-V$ characteristics of these series of solar cells deposited at different $F l_{\text {total }}$ are shown in Fig. 8. Similar dependencies of $\eta, V_{O C}, J_{\mathrm{SC}}$, and FF with the variation of SC are observed for all different $F l_{\text {total }}$. Compared with the hphP $60-\mathrm{W}$ series in Fig. 5, thinner $p$ layers in the hphP 100SCCM series increase the blue-light response and thus $J_{\mathrm{SC}}$, leading to higher efficiencies. At constant SC, solar cells deposited with higher $F l_{\text {total }}$ exhibit higher $V_{\text {OC }}$, suggesting a lower crystallinity in the $i$ layers. In Fig. $9, R_{D}, \eta$, and SC of the optimum cells, deposited with different $F l_{\text {total }}$ are shown. An increase in $F l_{\text {total }}$ from 100 to $400 \mathrm{SCCM}$ results in a

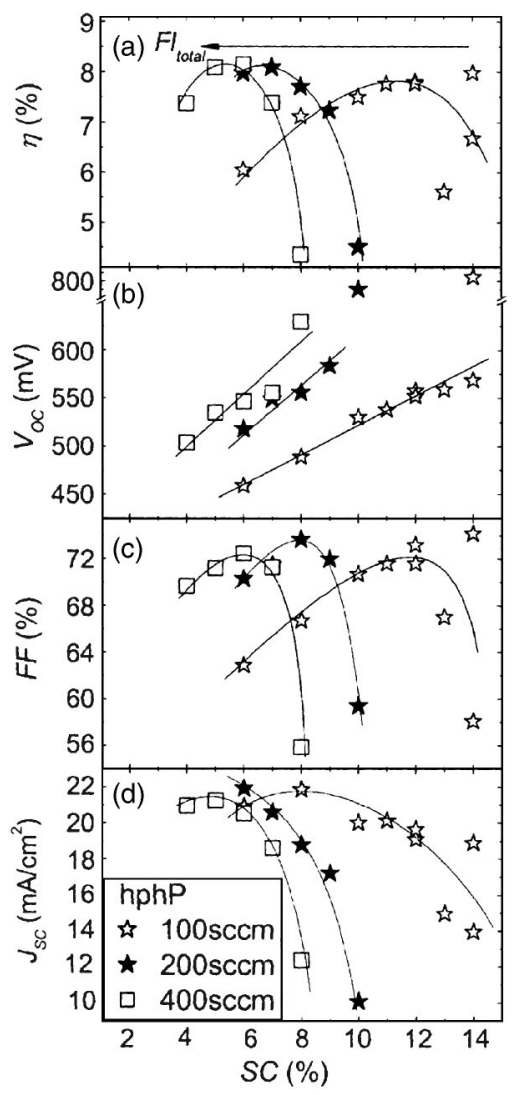

FIG. 8. $J-V$ characteristics (a) $\eta$, (b) $V_{\mathrm{OC}}$, (c) FF, and (d) $J_{\mathrm{SC}}$ under AM1.5 illumination of solar cells deposited under hphP conditions with different $F l_{\text {total }}$. All solar cells are $\sim 1-\mu \mathrm{m}$ thick. The $1 \times 1 \mathrm{~cm}^{2}$ large thermally evaporated Ag back contacts define the solar cell area. The arrow in figure (a) shows the systematic shift of the optimum cells' SC upon the increasing $\mathrm{Fl}_{\text {total }}$. The lines are guides to the eyes. 


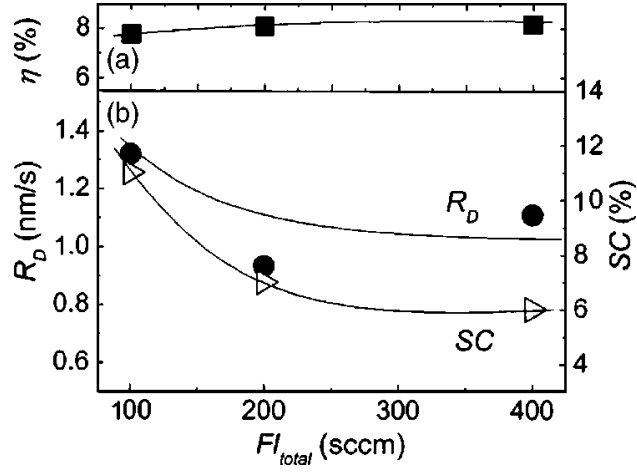

FIG. 9. (a) Efficiencies of the optimum solar cells in the SC series with different $F l_{\text {total }}$. (b) Corresponding deposition rates $R_{D}$ and SC of these cells.

slight increase of the $\eta$ of the optimum cells. At higher $F l_{\text {total }}$, the required SC for optimum solar cells is shifted to a lower $\mathrm{SC}$, leading to a lower $R_{D}$ for the optimum cells and suggesting a corresponding shift of the $\mu c-\mathrm{Si}: \mathrm{H} / a-\mathrm{Si}: \mathrm{H}$ transition.

Applying the optimized material of the hphP 100-SCCM series at a SC of $11 \%$, a thicker solar cell with $1.4-\mu \mathrm{m} i$-layer thickness was deposited at $1.2 \mathrm{~nm} / \mathrm{s}$. With the incorporation of the highly reflective $\mathrm{ZnO} / \mathrm{Ag}$ back contact, it shows a conversion efficiency of $9.2 \%$ (Fig. 10). An increase of the total flow rate up to $400 \mathrm{SCCM}$ decreases the $R_{D}$ of the optimum cell a little $(\sim 1.1 \mathrm{~nm} / \mathrm{s})$, but increase the efficiency. The $2.0-\mu \mathrm{m}$-thick optimum cell with $\mathrm{ZnO} / \mathrm{Ag}$ back contact shows a very high efficiency of $9.8 \%$ (also in Fig. $10)$.

Due to the considerable longer gas residence times under $\mathrm{hphP}$ conditions, powder formation is more pronounced than with a conventional low working pressure. However, powder formation did not affect the reproducibility and homogeneity of the solar cell preparation. Typically high-performance solar cells could be prepared up to a total layer thickness of at least $20 \mu \mathrm{m}$ in the reaction chamber before chamber cleaning was needed.

\section{Solar cell performance versus $\boldsymbol{R}_{D}$}

Applying the VHF-PECVD in the lplP and hphP regime, respectively, $\mu c-\mathrm{Si}: \mathrm{H}$ solar cells can be deposited over a

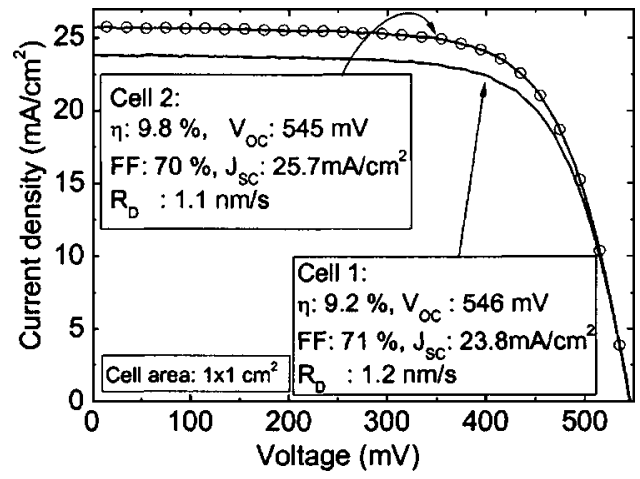

FIG. 10. High-efficiency solar cells deposited under hphP conditions with optimized $i$-layer thickness and $\mathrm{ZnO} / \mathrm{Ag}$ back contacts. Cell 1: hphP 100 SCCM, SC $=11 \%$, thickness $=1.4 \mu \mathrm{m}$. Cell 2: hphP $400 \mathrm{SCCM}, \mathrm{SC}=6 \%$, thickness $=2.0 \mu \mathrm{m}$. Cell area: $1 \times 1 \mathrm{~cm}^{2}$.

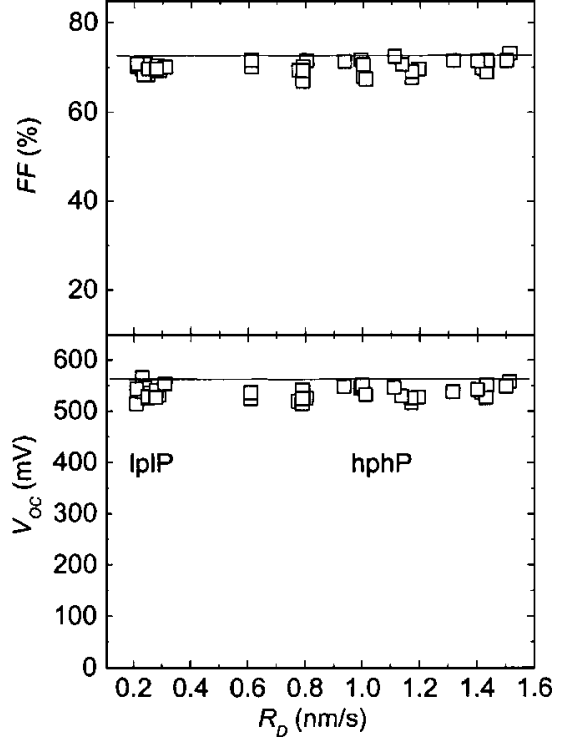

FIG. 11. FF and $V_{\mathrm{OC}}$ of the optimum $\mu c$-Si:H solar cells deposited under lplP and hphP conditions, plotted against $R_{D}$. Samples with $R_{D}$ above 0.6 $\mathrm{nm} / \mathrm{s}$ are deposited with hphP and those below $0.35 \mathrm{~nm} / \mathrm{s}$ with lplP. The lines in the figure are guides to the eyes as the upper limit of the two $J-V$ parameters.

wide range of $R_{D}$ between 0.2 and $1.5 \mathrm{~nm} / \mathrm{s}$ without a detrimental influence of the high deposition rate on the solar cell performance.

In Fig. 11, $V_{\mathrm{OC}}$ and $\mathrm{FF}$ of $\mu c$-Si:H solar cells with high conversion efficiencies are plotted against their $R_{D}$. FF and $V_{\mathrm{OC}}$ maintain constant high values of $\sim 72 \%$ and $\sim 550 \mathrm{mV}$, respectively, independent of $R_{D}$ and the deposition regime. $J_{\mathrm{SC}}$ is not taken into account here because it is easily affected by factors other than the $i$-layer properties, such as the type of substrate, the $p$-layer quality and thickness, and the $i$-layer thickness.

\section{B. Structural, optical, and electrical properties of solar cells}

To compare the properties of the $\mu c$-Si:H solar-cell absorber layers grown at different deposition conditions with different growth rates, it is essential to know the structural composition of the $i$ layer. As has been suggested above from the results of the solar cell $J-V$ parameters (Figs. 5 and 8), the variation of power and gas flow under hphP conditions shifts the $\mu c-\mathrm{Si}: \mathrm{H} / a-\mathrm{Si}: \mathrm{H}$ transition considerably to a different silane concentration SC. This shall be confirmed in the following through Raman-scattering experiments performed directly on the solar cells. Knowing the $I_{C}{ }^{\mathrm{RS}}$ values will allow to compare solar cells at similar crystalline volume fractions but prepared at very different deposition rates.

A further point of concern for solar cell materials prepared at a high deposition rate is that the $i$-layer absorber material might exhibit a structure evolution along the growth axis. The frequently observed interface or incubation layer with pronounced porosity and amorphous phase could be expected to be more developed, i.e., thicker, at higher growth rates. This was investigated in the present research by Raman depth-profile methods. 


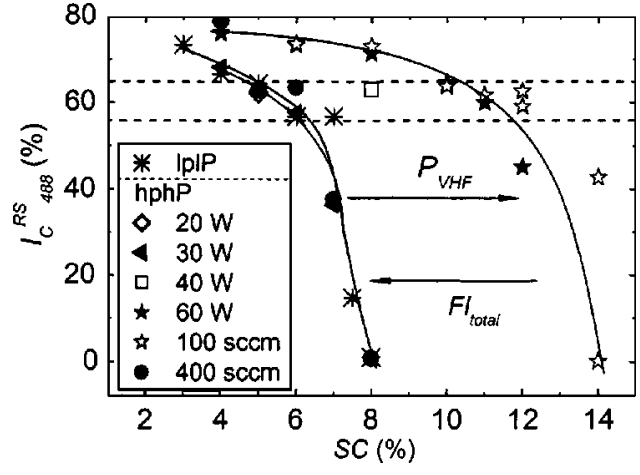

FIG. 12. 2. Raman-scattering intensity ratio with 488 -nm excitation, $I_{C}{ }_{488}$, of the lplP and hphP solar cells. Optimum solar cells in the SC series are found between the two dashed lines shown in the figure. Arrows in the figure indicate the shift of $I_{C} \mathrm{RS}$ 488 by applying higher $P_{\mathrm{VHF}}$ or $F l_{\text {total }}$. The lines are guides to the eyes.

Finally, the influence of different deposition rates on the electronic and optical properties of the $i$-layer absorber material in the $\mu c-\mathrm{Si}: \mathrm{H}$ solar cell is of interest. These properties, however, are not easily accessible. We shall try to obtain at least some information from the measurements of the dark $J-V$ characteristics and from quantum efficiency measurements.

\section{Raman-scattering experiments and structure depth profiles}

The $I_{C}{ }_{488}$ values are shown in Fig. 12 as a function of SC. For the hphP $20-\mathrm{W}$ and hphP $40-\mathrm{W}$ series, only the optimum cells were measured. A decreasing $i$-layer crystallinity with increasing SC can be observed in each series. Depositions with or without a shield around the cathode make no remarkable difference in the structure properties, comparing the hphP 60-W and hphP 100-SCCM series. Although the $\mu c-\mathrm{Si}: \mathrm{H} / a-\mathrm{Si}: \mathrm{H}$ transition occurs at different SC when different deposition conditions are applied, optimum cells, which can be found between the two dashed lines in this figure, are always obtained at the transition and show a similar crystallinity around $60 \%$. The results confirm the conclusions made from the $J-V$ parameters: An increase of $P_{\mathrm{VHF}}$ shifts the $\mu c-\mathrm{Si}: \mathrm{H} / a-\mathrm{Si}: \mathrm{H}$ transition to higher $\mathrm{SC}$ values; an increase of $F l_{\text {total }}$ shifts this transition to lower SC values. As $R_{D}$ in all cases increase with $\mathrm{SC}$, such shifts result in corresponding shifts of the deposition rates for optimum solar cells.

The structural development of three series of $\mu c-\mathrm{Si}: \mathrm{H}$ solar cells, hphP 30-W, hphP 60-W, and hphP 100-SCCM, prepared at medium and high deposition rates have been investigated by Raman-scattering measurements with different excitation wavelengths. The results are compared with similar studies of solar cells with standard lplP absorber layers. Figure 13 shows the $I_{C}{ }^{\mathrm{RS}}$ values calculated from a Raman spectra with 647-nm excitation $\left(I_{C}{ }_{647}\right)$, plotted against those with $488 \mathrm{~nm}\left(I_{C}{ }_{488}{ }_{48}\right)$. The deviation from the diagonal reflects the structure difference between the positions of the $i$ layer near the etched-away $n$ layer and close to the $p / i$ interface. The lplP samples deposited at a low $R_{D}$ show a very homogeneous distribution of the crystalline fraction along

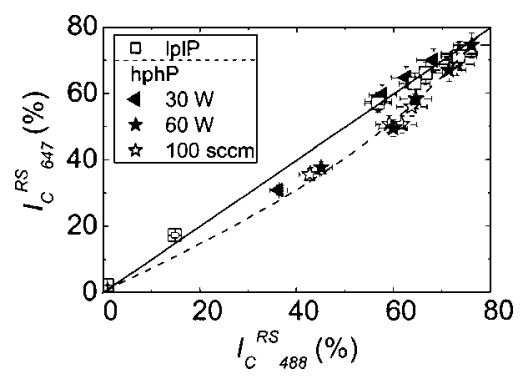

FIG. 13. $I_{C}{ }^{\mathrm{RS}}{ }_{647}$ of the $1 \mathrm{plP}$ and hphP solar cells plotted as a function of $I_{C}{ }^{\mathrm{RS}} 488$.

the growth direction, no matter if highly crystalline or almost amorphous. On the other hand, for the hphP solar cells, the $I_{C}{ }_{647}^{\mathrm{RS}}$ values are significantly smaller than $I_{C}{ }^{\mathrm{RS}}{ }_{488}$, indicating a structural evolution during the $i$-layer growth. In particular for the $I_{C}{ }^{\mathrm{RS}}{ }_{488}$ values around $60 \%$ where the optimum cells are obtained (see Fig. 12), a remarkable structurecomposition difference between top and bottom can be seen.

But the resolution in growth direction of this method with different wavelengths is, of course, not very high. The $I_{C}{ }_{647}^{\mathrm{RS}}$ values, considered here to emphasize more the contribution close to the $p / i$ interface, are still strongly affected by the surface-near region. In order to evaluate the crystallinity with a much better resolution at different stages of the $i$-layer growth, Raman measurements with 488-nm excitation were done on craters with different depths, which were etched into the solar cells by KOH. Figure 14 shows the $I_{C}{ }_{488}^{\mathrm{RS}}$ at different depths measured on the optimum solar cells of selected series. As the solar cells are all about $1-\mu \mathrm{m}$ thick, positions 0 and 1000 on the $x$ axis correspond to the position of the $n$ and $p$ layers, respectively. Consistent with the "different wavelength" method, the lplP solar cell exhibits very similar $I_{C}{ }_{488}{ }_{488}$ at different stages of growth, i.e., no structure evolution. For the hphP optimum solar cells, the structure development, already indicated in Fig. 13, is confirmed by this method. $I_{C}{ }_{488}$ differences of up to $20 \%$ between the top and the bottom of the $i$ layer can be observed.

It can be concluded that absorber layers grown with $\mathrm{hphP}$ at high deposition rates show considerable structure evolution along the growth axis, while the absorber layer material prepared with a much lower rate under lplP conditions have a very homogeneous structure composition. Sur-

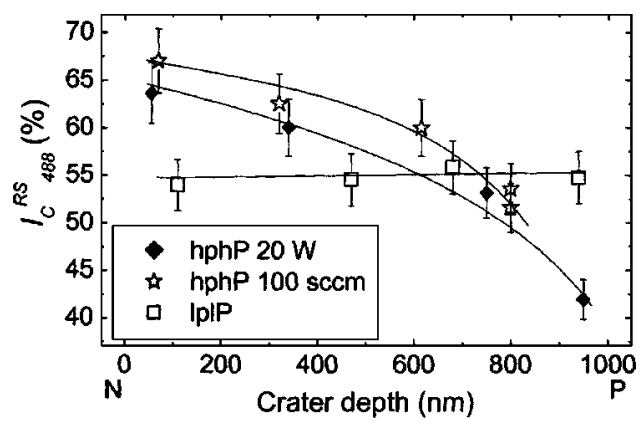

FIG. 14. The $I_{C}{ }_{488}^{\mathrm{RS}}$ at different depths in the $i$ layer show the structure development along the growth axis. Solar cells are optimum cells of three SC series deposited by lplP and hphP. For the 1- $\mu \mathrm{m}$-thick solar cells, crater depth of 0 and $1000 \mathrm{~nm}$ correspond to the $n$ and $p$ layers position, respectively. 


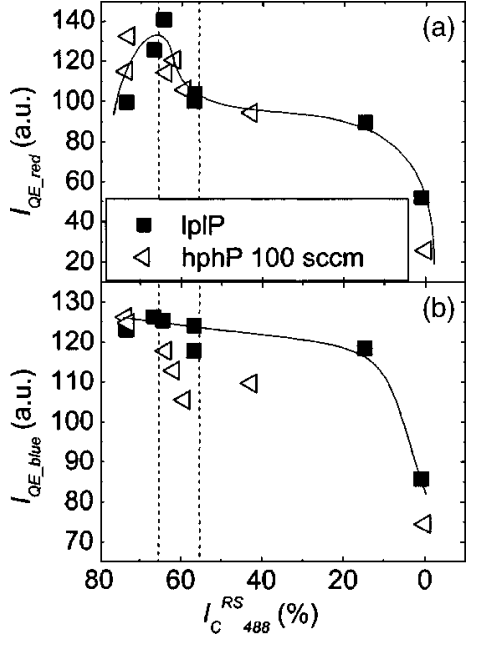

FIG. 15. The integrated intensities of the quantum efficiency, (a) $I_{\mathrm{QE}_{-} \text {red }}$ and (b) $I_{\mathrm{QE}}$ blue in long- and short-wavelength region, respectively, of the lplP and hphP 100-SCCM solar cells are plotted vs the $I_{C}{ }^{\mathrm{RS}}{ }_{488}$. The lines are guides to the eyes.

prisingly this does not result in a remarkable deterioration of the solar cell performance. As seen in Fig. 11, $V_{\mathrm{OC}}$ and FF, as a measure of the solar cell performance determined by the $i$-layer quality, are independent from the deposition rate.

\section{Quantum efficiency}

In an attempt to study the influence of structure development on the carrier generation and transport, quantum efficiency measurements were performed on two solar cell series, lplP and hphP 100 SCCM. In general, as the shortwavelength light will be fully absorbed in the $i$ layer close to the $p / i$ interface, the short-wavelength response can be considered as the criteria for the $p$ layer and $p / i$ interface quality. Long-wavelength light, with a lower absorption coefficient for microcrystalline silicon, will be homogeneously absorbed in the whole $1-\mu \mathrm{m}$-thick $i$ layer. We use the integrated intensity of QE between 300 and $520 \mathrm{~nm}, I_{\mathrm{QE} \text { blue }}$ to evaluate the short-wavelength response of solar cells and that between 650 and $1100 \mathrm{~nm}, I_{\mathrm{QE} \text { red }}$ for the long-wavelength response. In Figs. 15(a) and $15(\mathrm{~b})$ are $I_{\mathrm{QE} \text { blue }}$ and $I_{\mathrm{QE}}$ red of the lplP and hphP 100-SCCM series plotted against $I_{C}{ }_{488}^{\mathrm{RS}}$. Consistent with the highest $J_{\mathrm{SC}}$ in the region with intermediate crystallinity around 65\% (Figs. 5 and 8), the longwavelength responses of both series show maximum values in this range [Fig. 15(a)]. At the transition from a highly crystalline to an amorphous growth, the long-wavelength response decreases to lower values with the increasing amorphous phase in the $i$ layer.

On the other hand, the blue-light response shows a pronounced difference between the lplP and hphP solar cells. In the lplP series, with the exception of the blue response at the highest $I_{C}{ }^{\mathrm{RS}}{ }_{488}$ values, a higher $I_{\mathrm{QE}}$ blue can be seen in almost the entire $I_{C}{ }_{488}$ range. The differences in the shortwavelength response could be attributed to a deteriorated $p / i$ interface in the high-deposition-rate material. The presence of a more amorphous or thicker incubation layer, as concluded from the depth-profile methods, could lead to extraction problems for carriers generated near the $p / i$ interface.

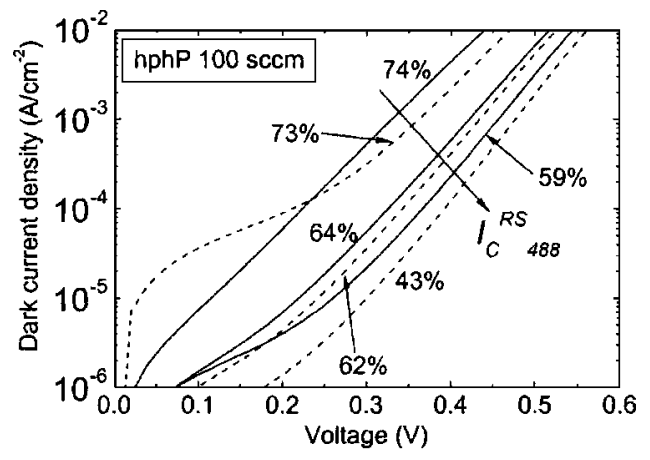

FIG. 16. The dark $J-V$ curves of the solar cells in the hphP 100-SCCM SC series. Numbers in the figure indicate $I_{C}{ }^{\mathrm{RS}}{ }_{488}$ values of the corresponding samples.

However, the high $\mathrm{FF}$ and high $V_{\mathrm{OC}}$ values in these $\mathrm{hphP}$ optimum cells indicate that apparently a moderate structure development in the growth direction is not a sufficient reason for bad solar cell performance. Still, a further improvement of the solar cells by an adjustment of the crystallinity at the $p / i$ interface could be possible.

\section{Dark J-V measurements}

A further possibility to obtain information about transport and recombination in the $i$ layers and at the interfaces of the $p-i-n \mu c-\mathrm{Si}: \mathrm{H}$ solar cells is the measurement of the dark $J-V$ curves. In Fig. 16, the dark $J-V$ curves of the solar cells of the hphP 100-SCCM series are shown exemplarily. With the decrease of $I_{C}{ }^{\mathrm{RS}}{ }_{488}$ a systematic shift of the curves to lower current densities can be observed, which can also be found in all the other SC series of Table I. According to the simple $p$ - $n$ diode theory, if the validity of its application to $\mu c-\mathrm{Si}: \mathrm{H}$ solar cells is assumed, the decrease in the current density with decreasing $I_{C}{ }_{488}{ }_{48}$ qualitatively explains the increase of $V_{\mathrm{OC}}$. Besides the shift of the curves, a change of the slope in the exponential range is also observed. The diode factor $n$ and saturation current density $j_{0}$ are calculated from the fitting of the exponential part of the dark $J-V$ curves to the diode equation $j_{\text {dark }}=j_{0}[\exp (\mathrm{eV} / n k T)-1]$, where shunt and series resistances have minor influence on the dark current density. The results are plotted for various solar cell series prepared at different deposition conditions versus $I_{C}{ }_{488}^{\mathrm{RS}}$ in Fig. 17. With the decrease of the $i$-layer crystallinity, the diode factor $n$ decreases from a value of about 1.85 at high $I_{C}{ }_{488}$ to about 1.4 at low crystalline volume fraction. Although there is some scatter, the values of $n$ and $j_{0}$ at constant $I_{C}{ }^{\mathrm{RS}}{ }_{488}$ show no systematic dependence on the deposition conditions or $R_{D}$ and show no clear trend with the change of deposition parameters. Only the values for the fully amorphous cells prepared at high deposition rates show a clear difference to the low-deposition-rate material. However, the evaluations of the measurement results are likely too ambiguous and based on too simplified assumptions, and therefore should not be overinterpreted.

\section{DISCUSSION}

High-efficiency solar cells have been deposited at high deposition rates by the combination of VHF discharge exci- 


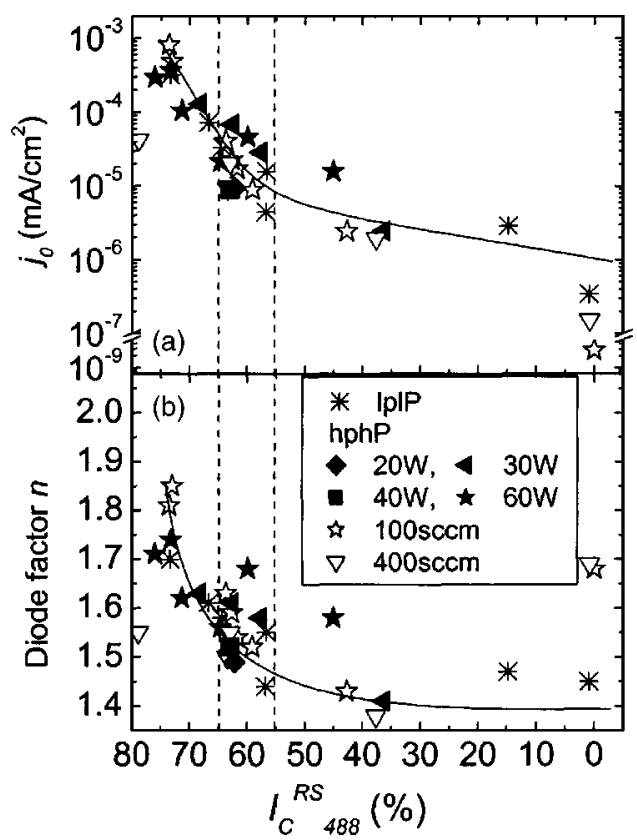

FIG. 17. (a) Saturation current density $j_{0}$ and (b) diode factor $n$ of the solar cells deposited by lplP and hphP, plotted as a function of $I_{C}{ }_{488}$. Optimum cells in different series are generally found between the two dashed lines in the figure. The lines are guides to the eyes.

tation with high process pressure and power. Presumably, this was made possible by an effective dissociation of the process gases, while keeping the damage through highenergy ion bombardment at a low level. Adequately homogeneous and stable deposition under the applied conditions were obtained by reactor-geometry adjustment, i.e., reduction of the electrode spacing and removal of the metallic shield around the powered electrode. With the constraint to the deposition process and chamber given by the chosen deposition conditions, it was found that the deposition rate does not increase by an increase in discharge power, but increases by higher gas flows, higher process pressure, and with wider electrode spacing. But under all investigated circumstances, the deposition rate increases linearly with silane concentration. On the other hand, variation in power or gas flow results in systematic shifts of the $\mu c-\mathrm{Si}: \mathrm{H} / a-\mathrm{Si}: \mathrm{H}$ transition. With an increase in power, the transition shifts to higher SC values, with an increase in the total flow rate, it shifts to lower SC values.

Like in previous reports on various deposition conditions or methods for $\mu c$-Si:H solar cell material, ${ }^{12,18,19}$ it was found that also with PECVD under VHF-hphP conditions optimum solar cells are prepared close to the transition from a highly crystalline to an amorphous growth with, as we shall call it, an optimum phase mixture (OPM) of $I_{C}{ }^{\mathrm{RS}}{ }_{488} \cong 60 \%$. Most importantly, it was found that a high solar cell performance is still available at considerably high deposition rates. As a result, a very high efficiency of $9.8 \%$ was achieved for a single-junction $p-i-n$ solar cell prepared at $1.1 \mathrm{~nm} / \mathrm{s}$.

For the exploration of new deposition regimes, our results demonstrate the importance to investigate the entire structure-composition range for $\mu c$-Si:H absorber layer material from highly crystalline to amorphous in order to find the deposition parameters for the OPM material.
In the following we shall discuss the influence of the deposition parameters under VHF-hphP conditions on the shift of the crystalline-to-amorphous growth conditions. An illustrative diagram, which considers the ratio of hydrogen over silane radicals as a major parameter, explains the shift of the region for the growth of OPM material. Furthermore, we shall discuss the influence of the high-deposition-rate processes on the material structure and the resulting solar cell performance.

\section{A. Structure adjustment for OPM $\mu c$-Si:H materials}

The various models proposed for the description of $\mu c$-Si:H growth, such as the partial chemical equilibrium ${ }^{29}$ or therewith related to the selective-etching model, ${ }^{30}$ the surface diffusion model, ${ }^{1}$ and the chemical annealing model,,${ }^{31,32}$ have in common that a high hydrogen radical density is considered to be critical for the formation of $\mu c-\mathrm{Si}: \mathrm{H}$. A recent study in the VHF-hphP regime shows a good agreement with the above results. ${ }^{33}$ To fulfil such conditions, $\mu c-\mathrm{Si}: \mathrm{H}$ is mostly prepared with a high dilution of the silicon precursor gas, usually silane, with hydrogen together with an effective dissociation of these gases by a high discharge power in PECVD or high filament temperatures in hot-wire chemical vapor deposition (HWCVD). If, in addition, a high growth rate is wanted, a further increase in the dissociation power might be needed. This leads to possible detrimental conditions for the $\mu c$-Si:H quality by high-energy ion bombardment in PECVD or a possible excess radiative heating in HWCVD. As a possible solution for high-growth conditions of $\mu c-\mathrm{Si}: \mathrm{H}$ without damage to the surface layer, the highpressure depletion method was proposed. ${ }^{3,11}$ In this approach, the application of a high discharge power is used to decompose most of the silane in initial reactions of the type $\mathrm{SiH}_{4} \rightarrow \mathrm{SiH}_{x}+(4-x) \mathrm{H}$. Under the silane-depletion condition, the reaction

$$
\mathrm{SiH}_{4}+\mathrm{H} \rightarrow \mathrm{SiH}_{3}+\mathrm{H}_{2},
$$

where silane molecules annihilate atomic hydrogen, will be suppressed and a high atomic hydrogen density is maintained. A high working pressure, which is much higher than the several ten pascals typically used in the conventional RFor VHF-PECVD techniques for $\mu c-\mathrm{Si}: \mathrm{H}$ growth, provides sufficient silane molecules and prevents detrimental ion damage. One of the consequences, when working under silanedepletion conditions, is that, if most of the silane molecules are decomposed into growth precursors, one would expect little increase in the deposition rate with an increase in discharge power.

With the results of the present report we can confirm the success of this approach. The results indicate "silane depletion," at least to some extent, although the term "depletion" is somewhat ambiguous. In how far the silane is depleted is also determined by other deposition parameters, such as the reactor geometry. Note that the increase of $R_{D}$ with an increase of electrode distance and pressure (Fig. 4) agrees with the assumption of silane depletion. With higher pressure, the total amount of silane in the reaction zone is increased. With higher electrode distance, the volume of the reaction zone 


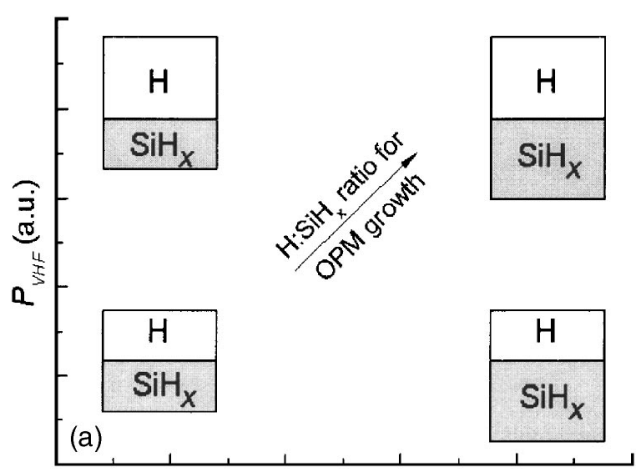

SC (a.u.)

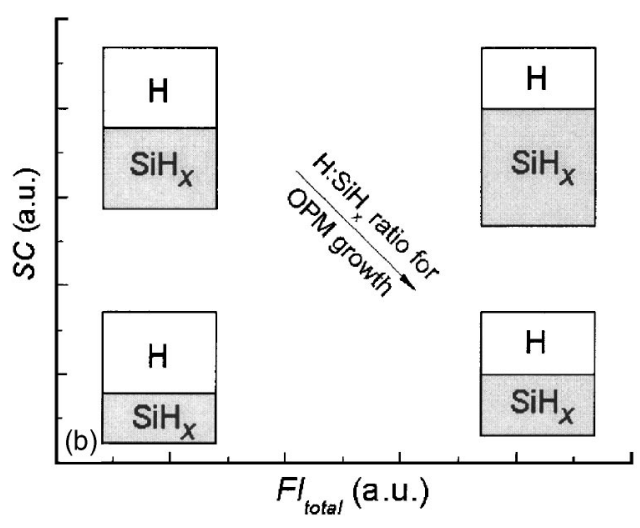

FIG. 18. Schematic diagrams of the amount of hydrogen and silane radicals (arbitrary units) (a) in the $\mathrm{SC}-P_{\mathrm{VHF}}$ parameter space and (b) in $\mathrm{SC}-F l_{\text {total }}$ parameter space under hphP conditions. To maintain the necessary $\mathrm{H} / \mathrm{SiH}_{x}$ ratio for growth of optimum phase mixture material, the $\mathrm{SC}$ has to be adjusted when varying $P_{\mathrm{VHF}}$ and $F l_{\text {total }}$. Areas of rectangles do not represent the exact radical densities.

between the electrodes is increased. In both cases more silane precursor gas is available to overcome the depletion conditions.

From the shift of the microcrystalline to amorphous growth conditions upon a variation of the process parameters, we propose that a proper ratio of atomic $\mathrm{H}$ over $\mathrm{SiH}_{x}$ $(x=1,2$, or 3$)$ should be maintained for the OPM material growth. Note that the contribution to the growth from individual radicals, such as $\mathrm{SiH}, \mathrm{SiH}_{2}$, or $\mathrm{SiH}_{3}$, will not be elaborated on in this paper. Let us first look at the influence of $P_{\mathrm{VHF}}$, which is visualized in the schematic diagram in Fig. 18(a). At low $P_{\mathrm{VHF}}$, a certain $\mathrm{H} / \mathrm{SiH}_{x}$ ratio for the OPM material growth is established by the choice of SC. A higher $P_{\text {VHF }}$ cannot produce more silicon-related precursors, due to the silane depletion in the whole investigated SC range (Fig. 4). But it will increase the atomic $\mathrm{H}$ density further, resulting in higher $\mathrm{H} / \mathrm{SiH}_{x}$ ratio. This effect does not lead to a higher $R_{D}$, but a higher crystallinity in the $i$ layer (confirmed by the results of Figs. 4 and 12). In order to compensate the increased hydrogen-radical density and maintain the required $\mathrm{H} / \mathrm{SiH}_{x}$ ratio for the OPM material growth, more silane has to be added to the plasma, leading to a higher $R_{D}$ for the optimum solar cell. The higher SC and $R_{D}$ for the optimum solar cells deposited at higher $P_{\mathrm{VHF}}$ support this interpretation, as indicated in Fig. 6.

Figure 18(b) illustrates the situation for different $F l_{\text {total }}$ which fits well into this picture, too. When a higher $F l_{\text {total }}$ is applied to an established OPM materials-growth condition, a higher $R_{D}$ will be generally observed because of the higher silane supply (see Fig. 7). But the increasing $\mathrm{SiH}_{x}$ radical and the possible atomic $\mathrm{H}$ annihilation effect by the excessive silane molecules result in a lower $\mathrm{H} / \mathrm{SiH}_{x}$ ratio, leading to a lower $i$-layer crystallinity. This is confirmed by the Ramanscattering measurements (Fig. 12) and by the $J-V$ parameters (Fig. 8) of the solar cells deposited with different $F l_{\text {total }}$. In order to maintain the proper ratio of atomic $\mathrm{H}$ over $\mathrm{SiH}_{x}$, one has to go to a lower SC at a higher $F l_{\text {total }}$. Note that Fig. 18 is just an illustrative picture and the rectangle areas do not represent the true radical densities.

Under high $F l_{\text {total }}$ conditions, the optimum solar cells are prepared at a lower $R_{D}$ than those at a low $F l_{\text {total }}$ although the total silane flow rate for the optimum cell is still higher. This is an indication of a lower gas utilization under high $F l_{\text {total }}$ conditions, resulting from a shorter gas residence time.

As the variation of $\mathrm{SC}$ is the most simple and straightforward method to adjust the $\mathrm{H} / \mathrm{SiH}_{x}$ ratio, we consider it mandatory for material and device optimization.

\section{B. Solar cell performance and $i$-layer properties}

The solar cell performance is essentially determined by the $i$-layer properties, if the other cell components, such as substrates and doped layers, are the same for the different solar cells and are not affected by the $i$-layer deposition. We have studied the transport properties of $\mu c-\mathrm{Si}: \mathrm{H}$ solar cells prepared by different techniques and at different deposition rates by dark $J-V$ and quantum efficiency measurements and correlated these with the results from Raman and Raman "depth profile" measurements. Based on various earlier reports about high-deposition-rate processes for intrinsic $\mu c$-Si:H absorber layers, including work in the hphP regime, ${ }^{34-36}$ one could have expected that the high-rate growth process has a negative influence on the material quality and the structure homogeneity along the growth axis. The results from the structure depth profile clearly show the existence of such a structure inhomogeneity in hphP material at high growth rates. Surprisingly this structure inhomogeneity is not reflected in an overall reduced solar cell efficiency under illumination as compared with a low-deposition-rate material (Fig. 11), but only in a lower short-wavelength response (Fig. 15). Also the evaluations of the dark $J-V$ curves indicate neither differences in the total defect density nor differences in the interface recombination between solar cells prepared with different regimes. Assuming the validity of the theory for $p$ - $n$ diodes as applied to $\mu c-\mathrm{Si}: \mathrm{H}$ solar cells, similar defect densities can be deduced from the similar $j_{0}$ in the solar cells with similar crystallinity and thickness [Fig. 17(a)]. Thus, a similar diode factor $n$ in the solar cells with the same crystallinity [in Fig. 17(b)] suggests no noticeable difference in the recombination at the interface. Detailed discussion about the $j_{0}$ and $n$ in $\mu c-\mathrm{Si}: \mathrm{H} p-i-n$ diodes can be found in Ref. 24. Further-support for similar bulk layer properties between high- (hphP) and low- (lplP) deposition-rate materials is given by the very similar $I_{\mathrm{QE}_{-} \text {red }}$ values in the quantum efficiency measurements for both types of solar cells. 
Another similarity between the lplP and hphP materials is that the optimum solar cells are always obtained at the $\mu c-\mathrm{Si}: \mathrm{H} / a-\mathrm{Si}: \mathrm{H}$ transition. In good agreement with previous results that a higher defect density was found in the highly crystalline material, ${ }^{37}$ the reduced $I_{\mathrm{QE}_{-} \text {red }}[$ Fig. 15(a)], the high diode factors $n>1.7$, and the high dark saturation current densities (Fig. 17) at the highest crystalline volume fractions suggest carrier extraction problems in the devices. In addition to the higher $V_{\mathrm{OC}}$ in the solar cells with an OPM material, higher FF in such cells suggests a lower bulk recombination and a better carrier extraction, as compared to the highly crystalline samples.

On the other hand, the considerable difference in bluelight response $I_{\mathrm{QE} \text { blue }}$ does indicate a difference at the $p / i$ interface in lplP and hphP solar cells with reduced carrier extraction from the interface-near region in hphP solar cells deposited at high $R_{D}$. Although this matches with the observed structure inhomogeneity, the FF remains at high levels above $70 \%$, indicating good carrier extraction from the bulk in these cells.

We summarize that the combination of high plasmaexcitation frequencies in PECVD together with high deposition pressures makes it possible to achieve high-rate growth of the OPM material without a negative influence on the solar cell $J-V$ parameters. All results suggest very good bulk layer properties with no indication for differences between high- and low-growth-rate material. This allows high-rate growth of high-efficiency solar cells. However, there are clear indications for structure inhomogeneity and deteriorated $p / i$ interfaces in the hphP material. This gives hope for even further improved solar cell performance at high deposition rates by reducing the structure development or improving the $p / i$ interface.

\section{v. CONCLUSIONS}

- A very effective growth regime for the deposition of $\mu c-\mathrm{Si}: \mathrm{H}$ solar-cell absorber layers with excellent quality at high deposition rates was identified. It uses VHFPECVD at high pressure and high power (hphP).

- Under all deposition conditions used, the highest solar cell efficiencies are obtained with optimum phase mixture (OPM) material grown close to the transition from a highly crystalline to an amorphous growth.

- Growth of the OPM material is strongly determined by a proper $\mathrm{H}$ over $\mathrm{SiH}_{x}$ ratio. This ratio is most easily controlled by a variation of the silane concentration. Corresponding silane concentration series are considered mandatory for a successful device optimization.

- The $\mu c-\mathrm{Si}: \mathrm{H}$ material quality is found not to be dependent on the deposition rate under VHF-PECVD hphP growth conditions in our investigated regime.

- The structure evolution along the growth axis found for the high-deposition-rate material, though without noticeable effect on the total solar cell efficiency, indicates the potential for further optimization of the presented growth process and the obtained device performance.

\section{ACKNOWLEDGMENTS}

The authors thank F. Birmans, M. Hülsbeck, S. Michel, W. Reetz, G. Schöpe, B. Sehrbrock, H. Siekmann, H. Stiebig, and $\mathrm{Ch}$. Zahren, for their constructive contribution to this work.

${ }^{1}$ A. Matsuda, J. Non-Cryst. Solids 59-60, 767 (1983).

${ }^{2}$ S. Vepřek, F.-A. Sarrot, S. Rambert, and E. Taglauer, J. Vac. Sci. Technol. A 7, 2614 (1989)

${ }^{3}$ M. Kondo, M. Fukawa, L. Guo, and A. Matsuda, J. Non-Cryst. Solids 266-269, 84 (2000).

${ }^{4}$ S. Suzuki, M. Kondo, and A. Matsuda, Sol. Energy Mater. Sol. Cells 74, 489 (2002).

${ }^{5}$ M. Heintze, R. Zedlitz, and G. H. Bauer, J. Phys. D 26, 1781 (1993).

${ }^{6}$ A. A. Howling, J.-L. Dorier, Ch. Hollenstein, U. Kroll, and F. Finger, J. Vac. Sci. Technol. A 10, 1080 (1992).

${ }^{7}$ F. Finger et al., J. Appl. Phys. 71, 5665 (1992).

${ }^{8}$ F. Finger, P. Hapke, M. Luysberg, R. Carius, H. Wagner, and M. Scheib, Appl. Phys. Lett. 65, 2588 (1994).

${ }^{9}$ H. Keppner, J. Meier, P. Torres, D. Fischer, and A. Shah, Appl. Phys. A: Mater. Sci. Process. 69, 169 (1999).

${ }^{10}$ J. K. Olthoff, R. J. Van Brunt, S. B. Radovanov, J. A. Flees, and R. Surowiec, J. Appl. Phys. 75, 115 (1994).

${ }^{11}$ L. Guo, M. Kondo, M. Fukawa, K. Saitoh, and A. Matsuda, Jpn. J. Appl. Phys., Part 2 37, L1116 (1998).

${ }^{12}$ T. Roschek, T. Repmann, J. Müller, B. Rech, and H. Wagner, J. Vac. Sci. Technol. A 20, 492 (2002).

${ }^{13}$ M. Fukawa, S. Suzuki, L. Guo, M. Kondo, and A. Matsuda, Sol. Energy Mater. Sol. Cells 66, 217 (2001).

${ }^{14}$ A. Lambertz, O. Vetterl, and F. Finger, Proc. of the 17th European Photovoltaic Solar Energy Conference, Munich, Germany, 22-26 Oct. 2001, edited by B. McNelis, W. Palz, H. A. Ossenbrink, and P. Helm (WIPMunich \& ETA-Florence, 2001), p. 2977.

${ }^{15}$ T. Matsui, M. Tsukiji, H. Saika, T. Toyama, and H. Okamoto, Jpn. J. Appl. Phys., Part 1 41, 20 (2002)

${ }^{16}$ U. Graf, J. Meier, U. Kroll, J. Bailat, C. Droz, E. Vallat-Sauvain, and A. Shah, Thin Solid Films 427, 37 (2003).

${ }^{17}$ Y. Mai, S. Klein, X. Geng, and F. Finger, Appl. Phys. Lett. 85, 2839 (2004).

${ }^{18}$ O. Vetterl et al., Sol. Energy Mater. Sol. Cells 62, 97 (2000).

${ }^{19}$ S. Klein, F. Finger, R. Carius, T. Dylla, B. Rech, M. Grimm, L. Houben, and M. Stutzmann, Thin Solid Films 430, 202 (2003).

${ }^{20}$ S. Klein, J. Wolff, F. Finger, R. Carius, H. Wagner, and M. Stutzmann, Jpn. J. Appl. Phys., Part 2 41, L10 (2002).

${ }^{21}$ O. Kluth et al., Thin Solid Films 351, 247 (1999).

${ }^{22}$ S. M. Sze, Physics of Semiconductor Devices, 2nd ed. (Wiley, New York, 1981).

${ }^{23}$ O. Vetterl, A. Lambertz, A. Dasgupta, F. Finger, B. Rech, O. Kluth, and H. Wagner, Sol. Energy Mater. Sol. Cells 66, 345 (2001).

${ }^{24} \mathrm{~T}$. Brammer and H. Stiebig, Technical Digest of the International PVSEC14, Bangkok, Thailand, 26-30 Jan. 2004, p. 655.

${ }^{25}$ P. Lechner, R. Geyer, H. Schade, B. Rech, and J. Müller, Proc. of 28th IEEE Photovoltaic Specialists Conference, Anchorage, Alaska, 15-22 Sept. 2000 (IEEE Inc., 2000), p. 861.

${ }^{26}$ T. Brammer, E. Bunte, H. Stiebig, F. Finger, and H. Wagner, Proc. of the 16th European Photovoltaic Solar Energy Conference, Glasgow, UK, 1-5 May 2000, edited by H. Scheer, B. McNelis, W. Palz, H. A. Ossenbrink, and P. Helm (James \& James Ltd., 2000), p. 545.

${ }^{27}$ L. Houben, M. Luysberg, P. Hapke, R. Carius, F. Finger, and H. Wagner, Philos. Mag. A 77, 1447 (1998).

${ }^{28}$ M. Luysberg, C. Scholten, L. Houben, R. Carius, F. Finger, and O. Vetterl, Mater. Res. Soc. Symp. Proc. 664, A15.2 (2001).

${ }^{29}$ S. Vepřek, Mater. Res. Soc. Symp. Proc. 164, 39 (1990).

${ }^{30}$ C. C. Tsai, G. B. Anderson, R. Thompson, and B. Wacker, J. Non-Cryst. Solids 114, 151 (1989).

${ }^{31}$ K. Nakamura, K. Yoshida, S. Takeoka, and I. Shimizu, Jpn. J. Appl. Phys., Part 1 34, 442 (1995)

${ }^{32}$ H. Shirai, J. Hanna, and I. Shimizu, Jpn. J. Appl. Phys., Part 2 30, L679 (1991).

${ }^{33}$ J. K. Rath, R. H. J. Franken, A. Gordijn, R. E. I. Schropp, and W. J. Goedheer, J. Non-Cryst. Solids 338-340, 56 (2004). 
${ }^{34}$ B. Rech, T. Roschek, T. Repmann, J. Müller, R. Schmitz, and W. Appenzeller, Thin Solid Films 427, 157 (2002).

${ }^{35}$ M. Kondo, H. Fujiwara, and A. Matsuda, Thin Solid Films 430, 130 (2003).
${ }^{36}$ C. Niikura, M. Kondo, and A. Matsuda, J. Non-Cryst. Solids 338-340, 42 (2004).

${ }^{37}$ A. L. Baia Neto, A. Lambertz, R. Carius, and F. Finger, J. Non-Cryst. Solids 299-302, 274 (2002). 